\title{
Exploration of Signal Transduction Pathways in Cerebellar Long-Term Depression by Kinetic Simulation
}

\author{
Shinya Kuroda, ${ }^{1,2}$ Nicolas Schweighofer, ${ }^{1}$ and Mitsuo Kawato ${ }^{1,3}$ \\ ${ }^{1}$ Kawato Dynamic Brain Project, ERATO, Japan Science and Technology, Kyoto 619-0288, Japan, 2Division of Signal \\ Transduction, Nara Institute of Science and Technology, Ikoma 630-0101, Japan, and 3ATR, Kyoto 619-0288, Japan
}

\begin{abstract}
Because multiple molecular signal transduction pathways regulate cerebellar long-term depression (LTD), which is thought to be a possible molecular and cellular basis of cerebellar learning, the systematic relationship between cerebellar LTD and the currently known signal transduction pathways remains obscure. To address this issue, we built a new diagram of signal transduction pathways and developed a computational model of kinetic simulation for the phosphorylation of AMPA receptors, known as a key step for expressing cerebellar LTD. The phosphorylation of AMPA receptors in this model consists of an initial phase and an intermediate phase. We show that the initial phase is mediated by the activation of linear cascades of protein kinase $C(P K C)$, whereas the intermediate phase is mediated by a mitogen-activated protein (MAP) kinase-
\end{abstract}

dependent positive feedback loop pathway that is responsible for the transition from the transient phosphorylation of the AMPA receptors to the stable phosphorylation of the AMPA receptors. These phases are dually regulated by the PKC and protein phosphatase pathways. Both phases also require nitric oxide (NO), although NO per se does not show any ability to induce LTD; this is consistent with a permissive role as reported experimentally (Lev-Ram et al., 1997). Therefore, the kinetic simulation is a powerful tool for understanding and exploring the behaviors of complex signal transduction pathways involved in cerebellar LTD.

Key words: cerebellar long-term depression; kinetics; simulation; signal transduction; positive feedback loop; phosphorylation
Cerebellar long-term depression (LTD), thought to be a molecular and cellular basis for cerebellar learning (Ito, 1989; Lisberger, 1998; Kawato, 1999), is a process involving a decrease in the synaptic strength between parallel fiber (PF) and Purkinje cells (PCs) induced by the conjunctive activation of PFs and climbing fiber (CF) (Ito, 1989; Linden and Connor, 1995). Multiple signal transduction pathways have been shown to be involved in this process (Linden and Connor, 1993; Fiala et al., 1996; Daniel et al., 1998). PF is thought to transmit its signal through glutamate (Kano and Kato, 1987; Linden et al., 1991) and nitric oxide (NO) (Shibuki and Kimura, 1997; Daniel et al., 1998), and $\mathrm{CF}$ is thought to transmit its signal through corticotropinreleasing factor (CRF) (Miyata et al., 1999) and $\mathrm{Ca}^{2+}$ influx via voltage-gated $\mathrm{Ca}^{2+}$ channels (Ekerot and Kano, 1985; Sakurai, 1990; Crepel and Jaillard, 1991; Linden and Connor, 1993; Daniel et al., 1998). Both PF- and CF-mediated signals are transmitted into PCs through multiple signaling pathways, including mitogenactivated protein (MAP) kinase and $\mathrm{Ca}^{2+}$, and finally lead to the phosphorylation of AMPA receptors by protein kinase C (PKC) (Fiala et al., 1996; Daniel et al., 1998; Matsuda et al., 2000). In addition, NO, by diffusing into PCs, inhibits protein phosphatase through the cGMP and soluble guanylnyl cyclase (sGC) pathways,

\footnotetext{
Received Feb. 26, 2001; revised May 4, 2001; accepted May 9, 2001.

S.K. was supported by the Inheritance and Variation Group, PRESTO (Japan Science and Technology Corporation, Japan). We thank G. Ferriol for his help in the kinetic simulation, M. Ito, T. Hirano, H. Qadota, K. Kaibuchi, and K. Doya for critically reading this manuscript, and K. Kurihara and N. Matsumoto for their technical assistance.

Correspondence should be addressed to Shinya Kuroda, Kawato Dynamic Brain Project, ERATO, Japan Science and Technology, 2-2-2 Hikaridai, Seika-cho, Souraku-gun, Kyoto 619-0288. E-mail: kshinya@erato.atr.co.jp.

N. Schweighofer's present address: Learning Curve, 2F Fuji Bldg 40, 15-14 Sakuragaoka-cho, Shibuya-ku, Tokyo 150-0031.

Copyright (C) 2001 Society for Neuroscience $0270-6474 / 01 / 215693-10 \$ 15.00 / 0$
}

resulting in inhibition of the dephosphorylation of AMPA receptors (Daniel et al., 1998). Therefore, the signals from PF and CF dually regulate the phosphorylation of AMPA receptors through the PKC and protein phosphatase pathways. The phosphorylation of AMPA receptors has been shown to be a key step for cerebellar LTD expression through internalization (Matsuda et al., 2000; Wang and Linden, 2000). However, because of the complex nature of the signaling pathways underlying the phosphorylation of AMPA receptors in cerebellar LTD, the systematic relationship between the synaptic inputs and the output responses remains obscure.

To understand and explore the behaviors of the complex signal transduction pathways, it is important to use the computational framework of kinetic simulation. Accordingly, by taking advantage of the recently developed program GENESIS/kinetikit (Bhalla and Iyengar, 1999), we built a computational simulation model for the phosphorylation of AMPA receptors in cerebellar LTD on the basis of kinetic parameters. It was reasonable to incorporate only biochemical parameters of post-translational biochemical reactions, but not those for gene expression and protein synthesis, into the simulation, simply because no kinetic parameters of gene expression and protein synthesis have thus far been available in cerebellar LTD. The phosphorylation of AMPA receptors in the kinetic model consisted of the initial and intermediate phases; the former was mediated by $\mathrm{Ca}^{2+}$, diacylglycerol (DAG), and arachidonic acid (AA)-mediated PKC pathway and the latter by the MAP kinase-mediated positive feedback loop pathway. In addition, NO was required for both the initial and intermediate phases, consistent with a permissive role as shown experimentally (Lev-Ram et al., 1997). Therefore, the kinetic simulation of cerebellar LTD provided us with a novel method 
for understanding and exploring the complex nature of the signal transduction pathways involved in cerebellar LTD.

\section{MATERIALS AND METHODS}

Block diagram showing the phosphorylation of AMPA receptors in cerebellar LTD. The conjunctive stimulation of PF and CF has been shown to elicit cerebellar LTD (Ito, 1989). In addition, multiple signal transduction pathways have been shown to regulate cerebellar LTD (Ito, 1989; Linden and Connor, 1993; Fiala et al., 1996; Daniel et al., 1998). According to the literature described below, a new block diagram of cerebellar LTD was reconstructed (see Fig. 1A). Cerebellar LTD has been shown to be mediated by the modulation of AMPA receptors (Linden and Connor, 1993; Daniel et al., 1998), and the decrease in the EPSP has been thought to be mediated by the internalization of phosphorylated AMPA receptors (Matsuda et al., 2000; Wang and Linden, 2000). PF mediates its signals to PCs by releasing glutamate, resulting in the activation of AMPA receptors and type-1 G-protein-coupled metabotropic receptors (mGluR1s) (Aiba et al., 1994; Conquet et al., 1994; Daniel et al., 1998; Ichise et al., 2000). The activation of AMPA receptors leads to an influx of $\mathrm{Ca}^{2+}$ through the activation of a $\mathrm{Na}^{+} / \mathrm{Ca}^{2+}$ pump (Brorson et al., 1994; Daniel et al., 1998) and to the activation of MAP kinase cascades through the activation of Lyn tyrosine kinase (Hayashi et al., 1999). The activation of mGluR1 leads to the activation of GTP-binding proteins, $\mathrm{Gq}$, and the subsequent activation of phospholipase C (PLC), resulting in the production of DAG and inositol-1,4,5-phosphate $\left(\mathrm{IP}_{3}\right)$ (Linden and Connor, 1993; Fiala et al., 1996; Daniel et al., 1998). $\mathrm{IP}_{3}$ mobilizes $\mathrm{Ca}^{2+}$ from the internal $\mathrm{Ca}^{2+}$ store through $\mathrm{IP}_{3}$ receptors (Finch and Augustine, 1998; Takechi et al., 1998). The elevation of $\mathrm{Ca}^{2+}$ leads to the activation of cytosolic phospholipase $\mathrm{A}_{2}\left(\mathrm{PLA}_{2}\right)$, resulting in the production of $\mathrm{AA}$ and the subsequent activation of PKC (Bhalla and Iyengar, 1999). PKC has been shown to be involved in the induction of cerebellar LTD (Crepel and Krupa, 1988; Linden and Connor, 1991). DAG, $\mathrm{Ca}^{2+}$, and AA activate protein kinase C (Nishizuka, 1992).

In addition, PF has recently been shown to produce NO (see Fig. $1 B$ ) (Shibuki and Kimura, 1997). NO, diff using into PCs, activates sGC, and the activated sGC catalyzes GTP into cGMP (Bredt and Snyder, 1992; Stone and Marletta, 1996; Lev-Ram et al., 1997; Daniel et al., 1998). Then, cGMP activates cGMP-dependent protein kinase (PKG) (Wang and Robinson, 1997). PKG phosphorylates its substrate, G-substrate (Nairn et al., 1985; Wang and Robinson, 1997). Recently, cDNA of G-substrate was cloned (Endo et al., 1999; Hall et al., 1999), and it was shown that phosphorylated G-substrate preferentially inhibits protein phosphatase 2A (PP2A) rather than protein phosphatase 1 (Endo et al., 1999). In this simulation, therefore, we assumed that the dephosphorylation of AMPA receptors is mediated by PP2A. CF has been known to depolarize PCs, resulting in the influx of $\mathrm{Ca}^{2+}$ into PCs through voltagegated $\mathrm{Ca}^{2+}$ channels (Ito, 1989; Linden and Connor, 1993; Daniel et al., 1998). In this study, therefore, $\mathrm{Ca}^{2+}$ elevation induced by the stimulation of $\mathrm{PF}$ and $\mathrm{CF}$, or $\mathrm{PF}$ or $\mathrm{CF}$ alone, was assumed on the basis of the experimental results using $\mathrm{Ca}^{2+}$ indicators (Miyakawa et al., 1992; Midtgaard et al., 1993; Kohda et al., 1995; Wang et al., 2000), not by the kinetic simulation. Recently, CRF found in CF was shown to play a permissive role in cerebellar LTD (Miyata et al., 1999) and to activate MAP kinase without $\mathrm{Ca}^{2+}$ elevation (Rossant et al., 1999). In this simulation, therefore, MAP kinase was activated by PKC, Lyn, and CRF through the activation of Raf and MAP/extracellular signal-regulated kinase (MEK). Activated MAP kinase phosphorylates and activates $\mathrm{PLA}_{2}$, resulting in the production of AA and the subsequent activation of PKC (Bhalla and Iyengar, 1999). Therefore, the PKC-MAP kinase pathway interacts at this point. This connection should result in a positive feedback loop (Bhalla and Iyengar, 1999). In this study, therefore, we attempted to set the parameters to fit the time course of the phosphorylation of the AMPA receptors to that of EPSP as reported previously (Chen and Thompson, 1995). We built the NO/cGMP pathway according to literature (see Fig. $1 B$, Table 1). All of the kinetic parameters in Figure $1 B$ are shown in Table 1. All of the other kinetic parameters used in this study were based on previous reports (Bhalla and Iyengar, 1999) and are shown on our web site (http://www.erato.atr.co.jp/ kuroda/ supplementary_info.html). All of the inputs used in this study are also shown in Appendix 1 (see Fig. 6).

Kinetic simulations. The phosphorylation of AMPA receptors in cerebellar LTD was simulated based on the following two biochemical reactions: protein-protein (molecule-molecule) interactions and enzymatic reactions. The protein-protein interactions included interactions such as NO-GS and cGMP-PKG. These reactions can be given by the following formulation:

$$
[A]+[B] \underset{K_{\mathrm{b}}}{\stackrel{K_{\mathrm{f}}}{\rightleftarrows}}[A B] .
$$

Experimentally, in most cases, $K_{\mathrm{f}}$ and $K_{\mathrm{b}}$ are not available in literature. However, $K_{\mathrm{d}}$, the dissociation constant, has generally been reported. Therefore, based on the reported $K_{\mathrm{d}}$ values, $K_{\mathrm{f}}$ and $K_{\mathrm{b}}$ were calculated by the following definition:

$$
K_{\mathrm{d}}=\frac{K_{\mathrm{b}}}{K_{\mathrm{f}}}
$$

If $A$ is greatly in excess, the total amount of product, $[A B]$, that can be formed is limited by the amount of $B$. Therefore, the reactions should follow the pseudo first-order reactions. When the half time $\left(t_{1} / 2\right)$ of the pseudo first-order reaction is experimentally obtained, $K_{\mathrm{f}}$ and $K_{\mathrm{b}}$ can be calculated by the following equation or by plotting $[A]$ versus apparent rate constant, which can be estimated from $t_{1 / 2}$, giving a line with a $y$-intercept of $K_{\mathrm{b}}$ and slope of $K_{\mathrm{f}}$ :

$$
t_{1 / 2}=\frac{0.693}{K_{\mathrm{f}}+K_{\mathrm{b}}} .
$$

The enzymatic reactions include phosphorylation and dephosphorylation. These reactions can be given by the following formulation of Michaelis-Menten:

$$
[E]+[S] \underset{K_{2}}{\stackrel{K_{1}}{\rightleftarrows}}[E S] \stackrel{K_{3}}{\longrightarrow}[E]+[P],
$$

where $E, S$, and $P$ denote enzyme, substrate, and product, respectively.

As in the case of protein-protein interactions, the values of $K_{1}$ and $K_{2}$ are not generally given in literature. However, $K_{3}$ can be calculated by the experimentally shown $K_{\text {cat }}$ value, given by $V_{\max }$ divided by the concentration of the enzyme. The values of $K_{\mathrm{m}}$ are also generally reported. Therefore, on the basis of the $K_{\mathrm{m}}$ and $K_{3}$ values, the values of $K_{1}$ and $K_{2}$ were calculated by the following definition:

$$
K_{\mathrm{m}}=\frac{K_{2}+K_{3}}{K_{1}}
$$

Unless apparent rate constants are available, we assume that $K_{2}$ is $\sim 2-20 \times$ greater than $K_{3}$ because $K_{2}$ is generally greater than $K_{3}$ in many enzymes.

Once the above parameters determined on the basis of the kinetic values were found to be robust enough to reproduce cerebellar LTD elicited under normal conditions (Chen and Thompson, 1995), we simulated the following experiments. All of the numerical computations were performed with the kinetics library, which is an extension to GENESIS (Bhalla and Iyengar, 1999).

\section{RESULTS}

\section{Building a kinetic simulation model for the phosphorylation of AMPA receptors in cerebellar LTD}

To develop a computational kinetics simulation for the phosphorylation of AMPA receptors in cerebellar LTD, we first developed a block diagram for the phosphorylation of AMPA receptors in cerebellar LTD on the basis of reported data (Fig. 1A). Because recent evidence has suggested that the phosphorylation of AMPA receptors is a key step for the expression of cerebellar LTD through the internalization of the phosphorylated AMPA receptors (Matsuda et al., 2000; Wang and Linden, 2000; Xia et al., 2000), we measured concentrations of phosphorylated and nonphosphorylated AMPA receptors. According to literature, cerebellar LTD involves the phosphorylation of AMPA receptors of PCs by both the activation of PKC (Crepel and Krupa, 1988; Linden and Connor, 1993; Fiala et al., 1996; Daniel et al., 1998; Matsuda et al., 2000) and the inhibition of protein phosphatase by 

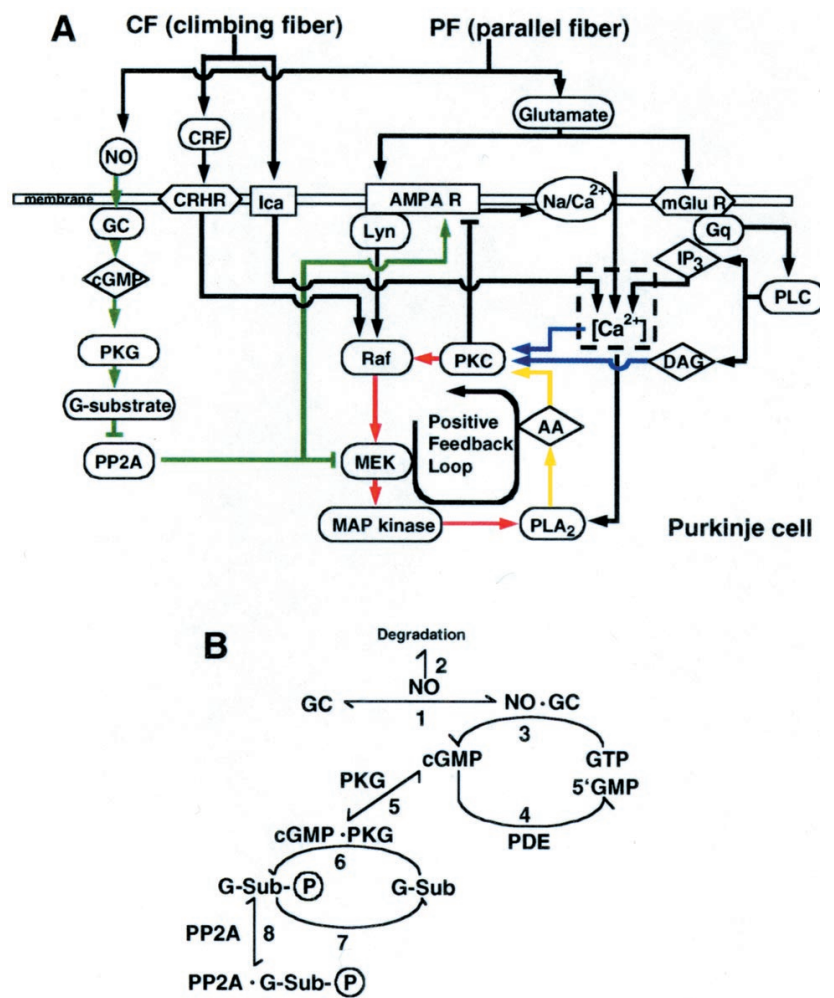

Figure 1. A, Block diagram of the phosphorylation of AMPA receptors in cerebellar LTD. The stimulation of PF and CF results in the elevation of the phosphorylation of AMPA receptors through the activation of PKC via the activation of both linear cascades, including DAG, $\mathrm{Ca}^{2+}$, and AA (blue and yellow lines), and a positive feedback loop including PLA $\mathrm{P}_{2}$ (pink and yellow lines), and through the inhibition of protein phosphatase $2 \mathrm{~A}$ ( green line). The dashed-line box indicates the generation of $\mathrm{Ca}^{2+}$, which was reconstituted by the previous observation (Miyakawa et al., 1992; Midtgaard et al., 1993; Kohda et al., 1995; Wang et al., 2000) but not by the kinetics simulation. The arrows and bars denote the stimulatory and inhibitory pathways, respectively. $B$, Detailed block diagram of the NO/ cGMP pathway. The bidirectional arrows denote reversible reactions, and the unidirectional arrows denote irreversible reactions. Enzymes are located in the middle of the segment. The numbers indicate the reactions that have kinetic parameters shown in Table 1. PDE, Phosphodiesterase.

the NO/cGMP pathway (Nairn et al., 1985; Ito and Karachot, 1992; Ajima and Ito, 1995; Daniel et al., 1998). Raf, MAP kinase, and PKC have been shown to form a potential positive feedback loop (Bhalla and Iyengar, 1999) (Fig. 1A, pink and yellow lines), and PKC has been shown to be regulated by the $\mathrm{Ca}^{2+}$-, DAG-, and AA-mediated linear pathway (Fig. $1 A$, blue and yellow lines) and by the positive feedback loop pathway. Because PP2A has been shown to be phosphorylated by PKG (Endo et al., 1999), we assume that the action of the NO/cGMP pathway is finally mediated by PP2A (Fig. $1 A$, green line, $B$, Table 1 ). Therefore, the phosphorylation of AMPA receptors is dually regulated by $\mathrm{PKC}$ and PP2A. In the block diagram (Fig. $1 A$ ), the number of initial concentrations of molecules was 28 . Of the 28,22 were determined by literature (Table 1 ) or by the kinetic simulation (Bhalla and Iyengar, 1999), and 6 were assumed. The numbers of protein-protein interactions and enzymatic reactions were 30 and 25 , respectively. Regarding the $K_{\mathrm{d}}$ values, 24 of a total of 30 reactions were determined by literature or by the kinetic simulation (Bhalla and Iyengar, 1999), and 6 were assumed. Regarding the values of $K_{\mathrm{m}}$ and $K_{\text {cat }}, 20$ of a total of 25 reactions were determined by literature or by the kinetics simulation (Bhalla and Iyengar, 1999), and 5 were assumed. The bistable behavior of the phosphorylation of AMPA receptors in cerebellar LTD (see below) was robust over a wide range of most of the assumed parameters, but it was very sensitive to parameters for PKC-Raf and PKCAMPA receptors because the former includes parameters for the intersection point of the positive feedback loop (see below), and the latter includes direct parameters for the phosphorylation of AMPA receptors. Taking advantage of the kinetic parameters available in literature with some assumptions, we built the computational kinetic simulation model of the phosphorylation of AMPA receptors in cerebellar LTD.

\section{The conjunctive stimulation of PF and CF induces the stable phosphorylation of AMPA receptors in cerebellar LTD}

On the basis of the kinetic parameters, we tried to make the kinetic simulation reproduce the experimental results, i.e., that the conjunctive stimulation of PF and CF induces cerebellar LTD (Chen and Thompson, 1995). Cerebellar LTD consists of an initial peak followed by a stable phase (Chen and Thompson, 1995). It has been shown that gene expression and protein synthesis are required for the late phase of cerebellar LTD (Linden, 1996); however, these experimental conditions are different from those of the kinetic simulation because, under the experimental conditions, only PCs were used, and the noninvolvement of NO was assumed (Linden, 1996). By considering the fact that only post-translational biochemical reactions were incorporated into the kinetic simulation, it is reasonable to assume that the stable phase of LTD can be divided into two phases: an intermediate phase maintained by the post-translational biochemical reactions and a late phase maintained by the protein synthesis and gene expression. Moreover, because the time course of the phosphorylation of AMPA receptors in cerebellar LTD has not been determined and the phosphorylation of AMPA receptors is important for the expression of cerebellar LTD, we assumed here that the phosphorylation of AMPA receptors also consists of three phases (initial peak, intermediate phase, and late phase) and built the simulation to reproduce the time course of EPSP in cerebellar LTD. In the kinetic simulation, the conjunctive stimulation of PF and CF was found to induce the phosphorylation of AMPA receptors and to reduce the concentration of nonphosphorylated AMPA receptors (Fig. $2 A$ ). The stimulation of either $\mathrm{PF}$ or $\mathrm{CF}$ alone failed to induce the stable phosphorylation of AMPA receptors in cerebellar LTD (Fig. 3). The time course of the phosphorylation of AMPA receptors consists of three phases: an initial phase including the initial peak of the phosphorylated AMPA receptors (0-10 $\mathrm{min})$, an intermediate phase including the sustained phosphorylation of AMPA receptors (10-40 min), and a late phase including the disappearance of the AMPA receptor phosphorylation $(>40 \mathrm{~min})$. The time course of the nonphosphorylated AMPA receptors in the initial and intermediate phases is similar to that of the amplitude of EPSP evoked by the conjunctive stimulation of PF and CF (Chen and Thompson, 1995) (Fig. 2A). In the late phase, however, the concentration of the nonphosphorylated AMPA receptors begins to increase and reaches the basal level at $\sim 90$ min because of the dephosphorylation of the AMPA receptors.

Consistently, the activation of PKC also consists of three phases (Fig. $2 B$ ): an initial phase mediated by the direct activation by $\mathrm{Ca}^{2+}, \mathrm{DAG}$, and $\mathrm{AA}$, an intermediate phase mediated by the activation of the MAP kinase-mediated positive feedback loop (Fig. 3D), and a late phase mediated by the inactivation of 


\begin{tabular}{|c|c|c|c|}
\hline \multicolumn{2}{|c|}{ Protein-protein interaction } & \multirow{2}{*}{$\frac{K_{\mathrm{d}}(\mathrm{nM})}{250}$} & \multirow{2}{*}{$\begin{array}{l}\text { Reference } \\
\text { Stone and Marletta (1996) }\end{array}$} \\
\hline 1 & & & \\
\hline 5 & & 50 & Ruth et al. (1993) \\
\hline 8 & & 270 & Endo et al. (1999) \\
\hline Enzymatic reaction & $K_{\mathrm{m}}(\mu \mathrm{M})$ & $K_{\text {cat }}(/ \mathrm{sec})$ & \\
\hline 3 & 45 & 7.35 & Wolin et al. (1982) \\
\hline 4 & 2 & 3.87 & Turko et al. (1998) \\
\hline 6 & 0.2 & 0.72 & Endo et al. (1999); Hall et al. (1999) \\
\hline Degradation & & $K(/ \mathrm{sec})$ & \\
\hline 2 & & $0.673^{a}$ & Wood and Garthwaite (1994) \\
\hline \multicolumn{4}{|l|}{ Dephosphorylation } \\
\hline 7 & & $0.0001^{a}$ & $b$ \\
\hline Molecule & \multicolumn{2}{|c|}{ Concentration $(\mu \mathrm{M})$} & \\
\hline $\mathrm{GC}$ & 3 & & Ariano et al. $(1982)^{c}$ \\
\hline GTP & 10 & & Bhalla and Iyengar (1999) \\
\hline PDE & 5 & & Kotera et al. $(1997,2000)^{c}$ \\
\hline PKG & 2.5 & & Lohmann et al. (1981) \\
\hline G-sub & 10.7 & & Detre et al. (1984) \\
\hline $\mathrm{PP} 2 \mathrm{~A}$ & 2.7 & & Mumby et al. (1985) \\
\hline
\end{tabular}

${ }^{a}$ The reactions were assumed to be first-order reactions.

${ }^{b}$ Assumption.

${ }^{c}$ The concentrations were assumed on the basis of reported data.

PKC activity (see also Fig. 5). This positive feedback loop is essential for the transition from the transient phosphorylation of AMPA receptors to the stable phosphorylation of the AMPA receptors and is responsible for the bistability of the AMPA receptor phosphorylation (Figs. 4, 5).

The PP2A activity markedly decreases by the stimulation and becomes lowest at $5 \mathrm{~min}$ and then gradually reactivates (Fig. $2 C$ ). The inactivation of PKC and the reactivation of PP2A lead to the dephosphorylation of the AMPA receptors, resulting in the disappearance of the phosphorylated AMPA receptors in the late phase. The reactivation of $\mathrm{PP} 2 \mathrm{~A}$ is mediated by the degradation of NO. Although NO is degraded very fast and consequently the PKG activity returns to the basal level after the stimulation (Fig. $3 E$ ), the reactivation of PP2A is very slow because the dephosphorylation step of G-substrate, an inhibitor of PP2A, is assumed to be quite slow. Because PP2A activity is inhibited by G-substrate phosphorylated by $\mathrm{PKG}$, it is interesting to test whether this prolonged phosphorylation of G-substrate really occurs in vivo if antibody that specifically recognizes the phosphorylated G-substrate will be available in the future. The inactivation of PKC activity is mediated by the degradation of $\mathrm{PKC}$ itself and by the reactivation of PP2A activity. Although the reactivation of $\mathrm{PP} 2 \mathrm{~A}$ is very small, this small reactivation of PP2A blocks the activation of the positive feedback loop, and the activity of the loop becomes lower than the threshold, which is a critical point for bistability, resulting in the transition from the activation state to the inactivation state of the loop. These results indicate that the current signal transduction pathways as shown in Figure 1 are able to produce the initial and intermediate phases for the phosphorylation of AMPA receptors in cerebellar LTD elicited by the conjunctive stimulation of $\mathrm{PF}$ and $\mathrm{CF}$.

\section{Requirement for the conjunctive stimulation of PF and CF to induce the stable phosphorylation of AMPA receptors}

Cerebellar LTD has been shown to be induced by the conjunctive stimulation of PF and $\mathrm{CF}$, but not by the stimulation of either PF or CF alone (Ito, 1989; Daniel et al., 1992; Hemart et al., 1994; Chen and Thompson, 1995). We therefore asked whether the stable phosphorylation of AMPA receptors also requires the conjunctive stimulation of both PF and CF. In the kinetic simulation, the stimulation of PF alone did not induce the intermediate phase of the phosphorylation of AMPA receptors, although the initial phase was induced to a lesser extent (Fig. 3, dotted line). The stimulation of CF did not induce either the initial or intermediate phase (Fig. 3, broken line). The difference between the initial phase by the stimulation of PF and that by the stimulation of $\mathrm{CF}$ was caused by the absence of $\mathrm{NO}$ production by the stimulation of CF, but not by that of PF. However, an experimental stimulation similar to the CF alone stimulation in the kinetic simulation has been shown to induce an initial sharp decrease in the EPSC (Daniel et al., 1992; Hemart et al., 1994). The failure of the kinetic simulation to reproduce this observation raises the possibility that other mechanisms in addition to the phosphorylation of AMPA receptors underlie the initial phase of cerebellar LTD (see Discussion).

\section{Optimal duration of the stimulation to induce the stable phosphorylation of AMPA receptors in cerebellar LTD}

We next examined what length of time of the conjunctive stimulation by $\mathrm{PF}$ and $\mathrm{CF}$ is required to induce the stable phosphorylation of AMPA receptors. In the simulation, the stable phosphorylation of AMPA receptors was not induced by a time $<3$ min (Fig. $4 A$ ). Time $>5$ min induced the stable phosphorylation 

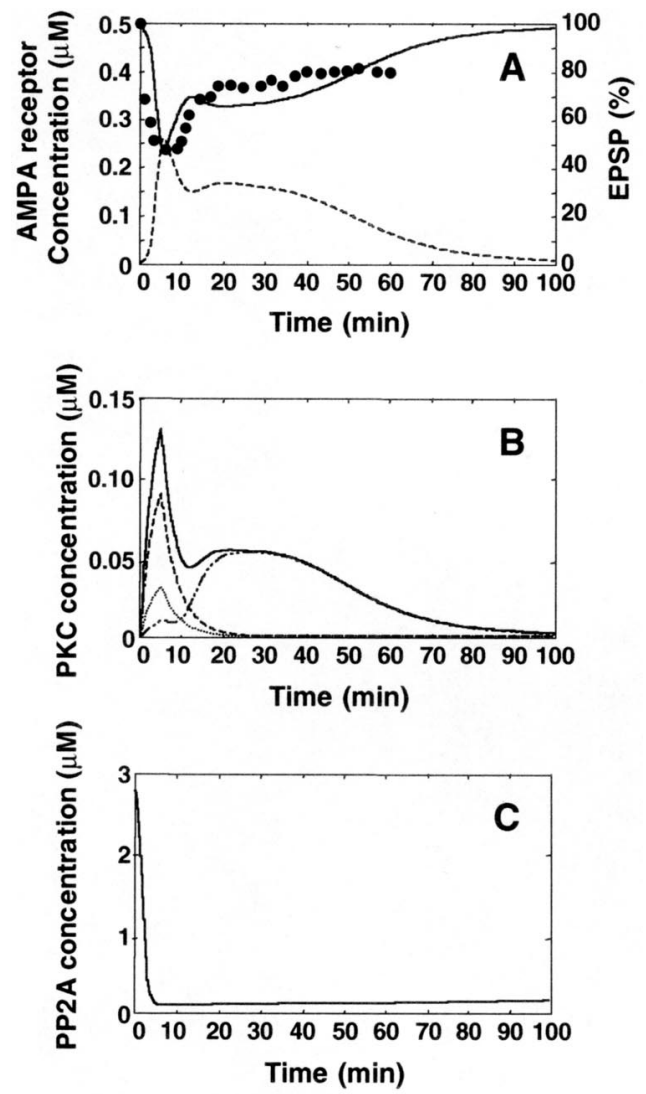

Figure 2. Conjunctive stimulation of $\mathrm{PF}$ and $\mathrm{CF}$ to induce the stable phosphorylation of AMPA receptors. The simulation was run at $1 \mathrm{~Hz}$ for a 5 min conjunctive stimulation of $\mathrm{PF}$ and $\mathrm{CF}$. The time course of the indicated molecule concentration is plotted. $A$, The phosphorylation of AMPA receptors induced by the conjunctive stimulation of PF and CF. The dashed line indicates the concentration for the phosphorylated AMPA receptors. The dark line indicates the concentration of the nonphosphorylated AMPA receptors. The changes of EPSP induced by the 10 min conjunctive stimulation of PF and CF is replotted (O) from the earlier observation (Chen and Thompson, 1995). Note that in the kinetic simulation, the 5 min stimulation of $\mathrm{PF}$ and $\mathrm{CF}$ is used because $5 \mathrm{~min}$ stimulation is optimal according to a previous report (Karachot et al., 1994). $B$, The activation of PKC by the stimulation. The dark line indicates the total PKC activity; the dashed line indicates $\mathrm{Ca}^{2+}$-activated PKC activity; the dotted line indicates DAG-activated PKC activity; the dashed-dotted line indicates AA-activated PKC activity. $C$, The inhibition of PP2A activity.

of AMPA receptors, and the optimal duration of the stimulation was found to be 6 min. The optimal duration in the simulation (6 min) of the phosphorylation of AMPA receptors was almost the same as that of the cerebellar LTD observed in an experiment (5 min) (Karachot et al., 1994). This result indicates that the phosphorylation of AMPA receptors shows bistability within a middle time scale of up to $40 \mathrm{~min}$. The activation of PKC also showed a similar bistability (Fig. 4B). The PP2A activity first decreased linearly and then reached a plateau (Fig. $4 C$ ), indicating that the inhibition of PP2A does not exhibit bistability. Therefore, the bistability in the phosphorylation of AMPA receptors is mediated by the prolonged activation of PKC. The activation of the MAP kinase-mediated positive feedback loop has been reported to be responsible for the bistability (Fig. 4D) (Bhalla and Iyengar, 1999). In addition, we found that the inhibition of PP2A is required for this bistability (Fig. 5). Because bistability in the phosphorylation of AMPA receptors has not been shown exper-
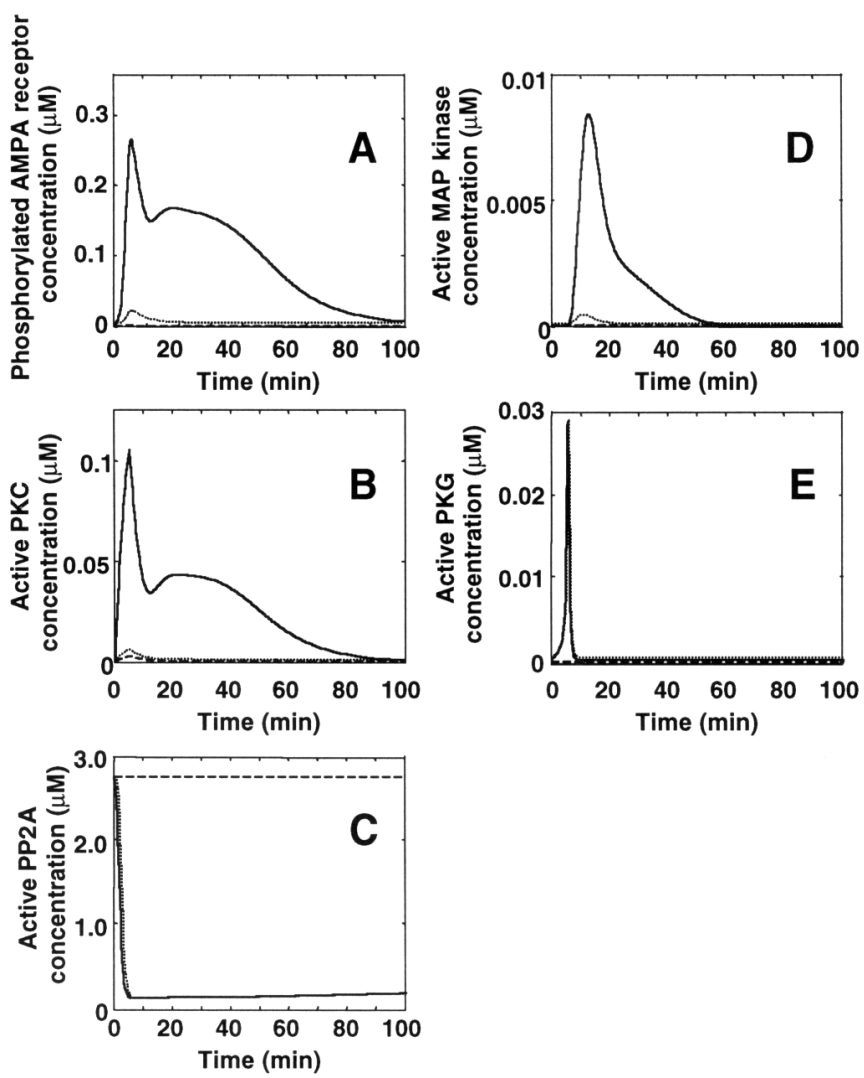

Figure 3. Requirement for the conjunctive stimulation of PF and $\mathrm{CF}$ to induce the stable phosphorylation of AMPA receptors. The simulation was run under conditions similar to those in Figure $2 A$ except that the following simulations were used: both $\mathrm{PF}$ and $\mathrm{CF}, \mathrm{PF}$ alone, or $\mathrm{CF}$ alone. The time courses of the indicated molecules by the conjunctive stimulation of PF and CF (straight line), by the stimulation of PF alone (dotted line), and by the stimulation of CF alone (dashed line) are plotted. $A$, The phosphorylated AMPA receptors; $B$, active PKC; $C$, active PP2A; $D$, active MAP kinase; $E$, active PKG.

imentally, this result provides an interesting testable prediction of bistability in the phosphorylation of AMPA receptors in cerebellar LTD. A recently established antiphosphorylated AMPA receptors antibody (Matsuda et al., 1999) should allow us to test this prediction in the future.

\section{The role of each signaling molecule and pathway in the induction of the phosphorylation of AMPA receptor in the cerebellar LTD}

We next explored the roles of signaling molecules and pathways in the phosphorylation of AMPA receptors (Fig. 5). Without PKC activation, the phosphorylation of AMPA receptors did not increase in the kinetic simulation (Fig. $5 A$, yellow line) because of the lack of activation of PKC (Fig. $5 B$ ). This finding is consistent with an earlier observation that the inhibition of PKC activity results in the complete disruption of LTD in mice expressing inhibitory peptide of PKC in PCs (De Zeeuw et al., 1998). In contrast, cerebellar LTD has been shown to be unimpaired in mice lacking the PKC $\gamma$ gene, one of the isoforms of PKC (Chen et al., 1995). This discrepancy may be attributable to the possibility that PKC isoforms function redundantly or that there is a PKC-independent pathway. Various experiments suggest the involvement of PKC in the induction of LTD (Linden and Connor, 1991; Ito and Karachot, 1992). Taken together, the former possibility is more likely. Without NO production, no stable phos- 

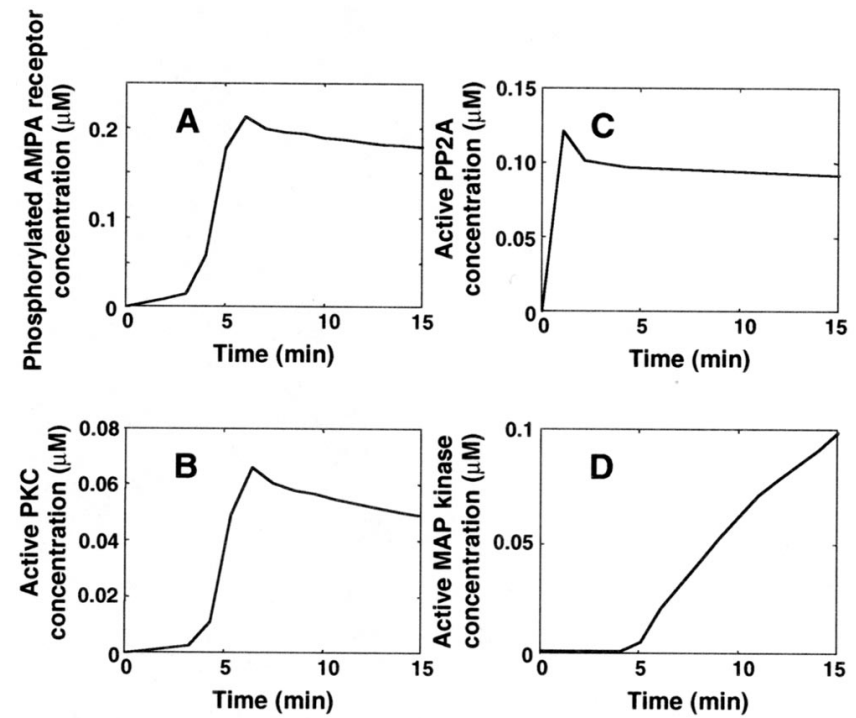

Figure 4. Optimal duration of the stimulation to induce the stable phosphorylation of AMPA receptors in cerebellar LTD. The duration of the conjunctive stimulation of $\mathrm{PF}$ and $\mathrm{CF}$ at $1 \mathrm{~Hz}$ was varied between 0 and $15 \mathrm{~min}$ with $1 \mathrm{~min}$ intervals, and the simulation was run. The concentrations of the phosphorylated AMPA receptors $(A)$, active PKC $(B)$, active PP2A $(C)$, and active MAP kinase $(D)$ at $30 \mathrm{~min}$ after the onset of the stimulation are shown.

phorylation of AMPA receptors was observed (Fig. 5A, green line) because of the lack of activation of PKG (Fig. $5 E$ ) and that of inhibition of PP2A (Fig. 5C), despite the fact that PKC was fully activated (Fig. $5 B$ ). This finding is consistent with the observation that NO is essential for the induction of all phases of LTD, although NO itself shows no ability to elicit LTD (Lev-Ram et al., 1997). In addition, these results support the idea that LTD is dually regulated by the PKC and NO pathways. Furthermore, without $\mathrm{Ca}^{2+}$ elevation, the stable phosphorylation of AMPA receptors did not occur with a lesser initial phase (Fig. 5A, pink line) because of the partial activation of PKC (Fig. $5 B$ ). This finding is also consistent with the fact that $\mathrm{Ca}^{2+}$ is essential for the induction of all phases of LTD (Sakurai, 1990; Konnerth et al., 1992). Without DAG elevation, both the initial and intermediate phases of the AMPA receptor phosphorylation were observed, but the phosphorylation was less stable compared with that under the normal condition (Fig. 5 A, black line) because of the partial activation of MAP kinase (Fig. 5D). This finding indicates that DAG contributes to the stable phosphorylation of AMPA receptors in both the initial phase and the intermediate phase. Experimentally, it is difficult to analyze the role of DAG because no specific inhibitors of DAG are available. Moreover, the inactivation of PLC, which produces both DAG and $\mathrm{IP}_{3}$, results in the depletion of both products. Consequently, the simulation is useful for analyzing the role of signal transduction pathways, which is experimentally difficult to analyze. Without $\mathrm{PLA}_{2}$ activation, the intermediate phase of the AMPA receptor phosphorylation disappeared, with a slight reduction in the initial phase (Fig. 5A, cyan line). The positive feedback loop was responsible for the intermediate phase because without MAP kinasemediated $\mathrm{PLA}_{2}$ activation, the intermediate phase disappeared without affecting the initial phase (Fig. $5 A$, purple line) because of the lack of the stable activation of MAP kinase (Fig. 5D). Lack of the activation of either Raf or MEK resulted in the same results as that without MAP kinase-mediated $\mathrm{PLA}_{2}$ activation. This finding indicates that the positive feedback loop including PLA $\mathrm{A}_{2}$ is responsible for the intermediate phase of the AMPA receptor phosphorylation. This result is consistent with an earlier observation that $\mathrm{PLA}_{2}$ regulates the intermediate phase of LTD (Linden, 1995). Without the activation of $\mathrm{PLA}_{2}$ by $\mathrm{Ca}^{2+}$ elevation, the initial phase came to be slightly reduced, and the intermediate phase came to be less stable (Fig. 5A, brown line).

\section{DISCUSSION}

The initial phase of the AMPA receptor phosphorylation in cerebellar LTD was dependent on the direct activation of PKC by linear cascades including DAG, $\mathrm{Ca}^{2+}$, and $\mathrm{AA}$, whereas the intermediate phase was mediated by the activation of the positive feedback loop. The inactivation of $\mathrm{PLA}_{2}$ resulted in the disappearance of the intermediate phase without a remarkable change in the initial phase, indicating that the positive feedback loop was responsible for the intermediate phase. Consistent with this result, the selective inhibition of $\mathrm{PLA}_{2}$ has been reported to convert cerebellar LTD to short-term depression (STD), and the application of free unsaturated fatty acids has been shown to result in an apparent conversion from STD to LTD in cultured PCs by the stimulation, where STD, not LTD, comes to be normally induced (Linden, 1995). Taken together, it is likely that PLA 2 and AA serve as regulators of the positive feedback loop and are responsible for the intermediate phase of LTD.

The lack of the activation of Raf, MEK, or MAP kinase led to the same result as that without the MAP kinase-mediated PLA activation. MAP kinase and MEK have also been shown to be required for the induction of both the initial and intermediate phases of cerebellar LTD (Kawasaki et al., 1999). The reason that MAP kinase and MEK are not involved in the induction of the initial phase in the simulation may be attributable to the possibility that an unknown part of the MAP kinase cascade is missing in the simulation. MAP kinase has been shown to be required for the mGlu receptor activity (Kawasaki et al., 1999). Therefore, the molecular linkage between MAP kinase and mGlu receptors needs to be clarified and incorporated into the kinetic simulation.

In all phases, the inhibition of PP2A by NO is essential for the phosphorylation of AMPA receptors. This is consistent with an earlier observation that NO is essential for cerebellar LTD, but NO itself is insufficient to induce LTD (Lev-Ram et al., 1997), suggesting that PP2A acts as a gate signal of cerebellar LTD. This result indicates that a significant amount of $\mathrm{PF}$ stimulation is required to induce cerebellar LTD via inhibition of PP2A, and that spontaneous PF activity may be insufficient to inhibit PP2A activity enough to be required for the stable phosphorylation of AMPA receptors. If only a small amount of $\mathrm{PP} 2 \mathrm{~A}$ is easily inhibited by spontaneous PF activity, the PF activity together with spontaneous CF activity may cause unexpected and unwarranted cerebellar LTD. Therefore, the reason such a large amount of PP2A is needed may be caused partially by the role of the NO-PP2A pathway as a gate signal for the induction of cerebellar LTD. In this study, spontaneous PF activity was not included. However, if spontaneous PF activity is included, the PP2A may reach to the some basal level, which may not be small enough to induce LTD, and should be inhibited further by NO signal, leading to induced LTD. Therefore, with or without spontaneous PF activity, the action of PP2A would be similar. In addition, PP2A has another role in the kinetic simulation; the dephosphorylation of Raf and MEK. Raf and MEK regulate the positive feedback loop, and the inhibition of the dephosphorylation of these molecules was required for the activation of the 

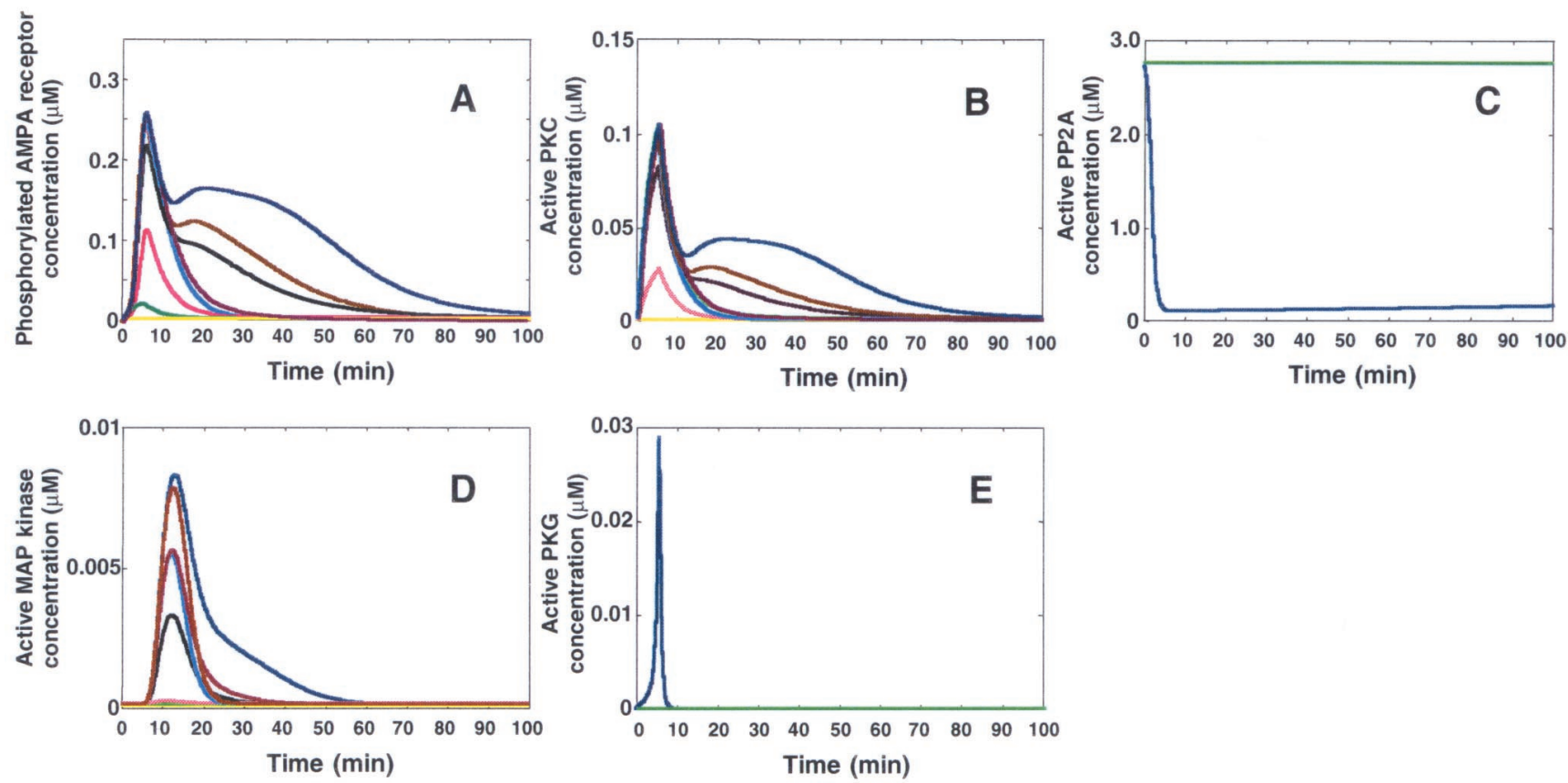

Figure 5. The role of each signaling molecule and pathway in inducing the phosphorylation of AMPA receptors in cerebellar LTD. To explore the roles of the signaling molecules and pathways in inducing the phosphorylation of AMPA receptors in cerebellar LTD, the simulation was run under the same conditions as in Figure $2 \mathrm{~A}$ except that the concentration of the indicated molecules shown below was held at the basal level or the indicated pathway was deleted. $A$, The phosphorylated AMPA receptors; $B$, active PKC; $C$, active PP2A; $D$, active MAP kinase; $E$, active PKG. Blue line, None; yellow line, $\mathrm{PKC}$; green line, $\mathrm{NO}$; pink line, $\mathrm{Ca}^{2+}$; cyan line, $\mathrm{PLA}_{2}$; black line, $\mathrm{DAG} ;$ brown line, $\mathrm{PLA}_{2}$ activated by $\mathrm{Ca}^{2+}$ elevation; purple line, $\mathrm{PLA} \mathrm{A}_{2}$ activated by MAP kinase. Note that the time courses of the active PP2A $(C)$ or active PKG $(E)$ were exactly the same, except without NO (green), and expressed as a single blue line.

positive feedback loop. Therefore, PP2A also has a permissive role in the phosphorylation of AMPA receptors as well as in the activation of the positive feedback loop.

We compared the phosphorylation of AMPA receptors in the kinetic simulation and cerebellar LTD shown experimentally. In the initial phase, some results of the AMPA receptor phosphorylation in the kinetic simulation did not correlate with the experimental observations of cerebellar LTD. The stimulation of CF alone did not induce an apparent initial phase in the kinetic simulation (Fig. 3), whereas a similar protocol can induce an initial sharp peak of EPSC decrease (Daniel et al., 1992; Hemart et al., 1994). Additionally, without $\mathrm{NO}$ or $\mathrm{Ca}^{2+}$ elevation, a small peak in the phosphorylation of the AMPA receptors could still be observed in the kinetic simulation (Fig. $5 A$ ), whereas this initial peak was not observed by the addition of blockers of $\mathrm{Ca}^{2+}$ (Sakurai, 1990; Eilers et al., 1997) or NO (Lev-Ram et al., 1997). These discrepancies raise the possibility that other mechanisms underlie the expression of the initial phase of cerebellar LTD. It has been shown that increasing $\mathrm{Ca}^{2+}$ in dendrite activates $\mathrm{Ca}^{2+}$ dependent $\mathrm{K}^{+}$channels, resulting in shunting PF-induced EPSP (Gruol et al., 1991; Khodakhah and Ogden, 1993; Muller et al., 1998). Additionally, it has been shown recently that the activation of postsynaptic mGluR1 in PC dendrites transiently depresses synaptic transmissions at PF-PC synapses by presynaptic mechanisms involving $\mathrm{Ca}^{2+}$ increase in PC dendrites and retrograde signaling (Levenes et al., 2000) and that retrograde inhibition of $\mathrm{Ca}^{2+}$ influx occurs through endogenous cannabinoids at excitatory synapses on PCs (Kreitzer and Regehr, 2001). These mechanisms are likely to be the main mechanisms for the expression of the initial phase of cerebellar LTD. The kinetic parameters in these two mechanisms, although unknown at present, should allow us to test whether these mechanisms can explain the expression of the initial phase of cerebellar LTD by use of the kinetic simulation. Accordingly, the kinetics simulation is a powerful tool for testing whether the phosphorylation of AMPA receptors can explain the expression of cerebellar LTD. Lists of the kinetic simulation results, the corresponding experimental results, and model predictions are summarized in Appendix 2.

The phosphorylation of AMPA receptors has been shown to trigger the internalization of phosphorylated AMPA receptors (Matsuda et al., 2000; Wang and Linden, 2000). A recent study has demonstrated that, in cortical neurons, the activation of AMPA receptors without the activation of NMDA receptors leads to the rapid and almost complete internalization of AMPA receptors within $5 \mathrm{~min}$ after the stimulation and the slow reinsertion of the AMPA receptors to the cell surface, resulting in a reduction in the number of AMPA receptors at the cell surface (Ehlers, 2000). It is possible that a similar mechanism is involved in cerebellar LTD. Taken together with our results, it is likely that the phosphorylation of AMPA receptors is a key step for cerebellar LTD expression through the internalization of the AMPA receptors at least in the intermediate phase. However, the internalization of phosphorylated AMPA receptors was not incorporated into our model because of the absence of kinetic parameters. The absence of phosphorylated AMPA receptor internalization in the kinetic simulation may affect the results by affecting the balance between the phosphorylated and nonphosphorylated AMPA receptor concentrations; however, it is likely that the results would be similar if the internalization step was incorporated into kinetic simulation because the internalization process itself does not affect the signaling pathways. If the kinetic parameters of the phosphorylated AMPA receptor internaliza- 

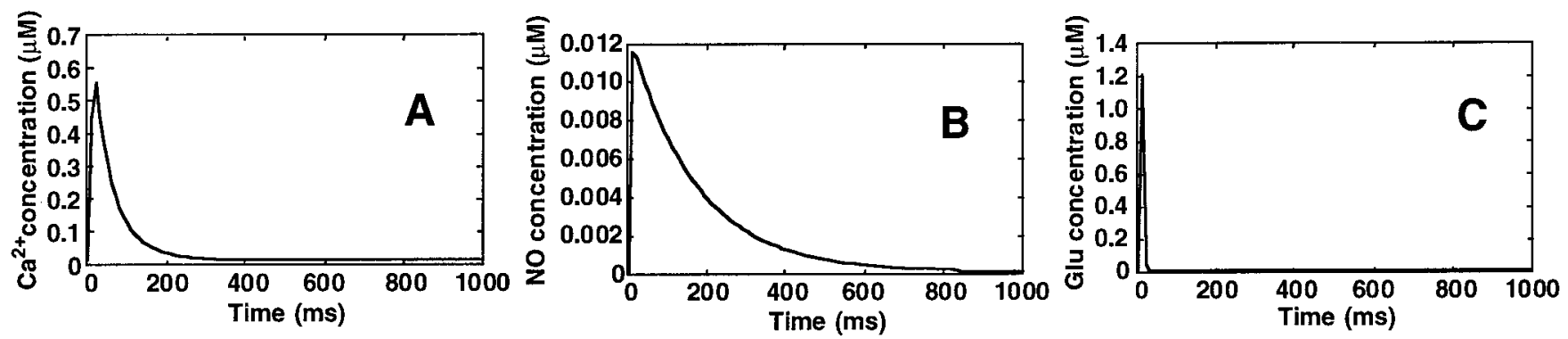

Figure 6. The inputs used in this study. The temporal waveforms of inputs, such as $\mathrm{Ca}^{2+}(A), \mathrm{NO}(B)$, and glutamate $(C)$, which are induced by a single stimulation of $\mathrm{PF}$ and $\mathrm{CF}$, are shown.

tion is determined, we can address the question of whether the phosphorylation of AMPA receptors and the subsequent internalization of the AMPA receptors can explain the intermediate phase as well as the initial phase of cerebellar LTD.

There are some discrepancies of the signaling pathways between the slice and the culture conditions. However, cerebellar LTD can be elicited robustly under both conditions. For example, under some experimental conditions (Linden et al., 1991, 1995), NO is not thought to be essential for the induction of cerebellar LTD. It is possible that the concentration or the activity of PP2A decreases, or that an unidentified molecule except NO regulates the PP2A pathways to compensate and induce LTD under such conditions. Additionally, no evidence of the roles of $\mathrm{PLA}_{2}$ and AA has been demonstrated in the slice condition. If this positive feedback loop does not work in the slice, then an alternative feedback loop such as the Rap1-MAP kinase-mediated positive feedback loop found in PC12 cells (York et al., 1998) is responsible for the intermediate phase. The fact that cerebellar LTD robustly occurs under both conditions strongly suggests that LTD is elicited by similar mechanisms in both conditions even if detailed mechanisms are different. If one pathway operates in only one of the conditions, changing the concentration of molecules of a certain type might compensate and induce the cerebellar LTD, or another redundant pathway having a similar characteristics might come to be a replacement. Therefore, despite the discrepancies between these conditions, the kinetic simulation model is still useful for understanding the mechanism of cerebellar LTD.

It has been shown that glial fibrillary acidic proteins (Shibuki et al., 1996), expressed in astrocytes but not in neurons, and the $\delta 2$ subunit of the glutamate receptor channels (Hirano et al., 1995; Kashiwabuchi et al., 1995) are essential for the induction of LTD. The phosphorylation of AMPA receptors has been shown to lead to the internalization of the AMPA receptors (Matsuda et al., 2000; Xia et al., 2000). Although the detailed mechanisms are still unknown, the molecules and mechanisms involved should be incorporated into the kinetics model in the future. Local $\mathrm{Ca}^{2+}$ release within the dendritic spines of PCs has been shown recently to be required for LTD induction (Miyata et al., 2000). Therefore, the specific localization of molecules and accessibility should also be quantitatively determined and incorporated into the kinetics model. In addition to phosphorylation, $\mathrm{Ca}^{2+}$ dependent $\mathrm{K}^{+}$channels (Gruol et al., 1991; Khodakhah and Ogden, 1993; Muller et al., 1998), presynaptic retrograde signaling (Levenes et al., 2000), and retrograde inhibition of presynaptic $\mathrm{Ca}^{2+}$ influx by endogenous cannabinoids (Kreitzer and Regehr, 2001) have been shown to underlie the expression of cerebellar LTD. Electrical processes, such as the channel activity of AMPA receptors and $\mathrm{Ca}^{2+}$-dependent $\mathrm{K}^{+}$channels, coupled with biochemical processes should also be incorporated into the kinetic simulation, provided the apparent kinetic parameters come to be determined. Moreover, the role of Raf in the induction of LTD has yet to be shown experimentally. Therefore, the present kinetic simulation should not be regarded as a definitive model, but as a complementary method for exploring cerebellar LTD in addition to experimental methods. It should also be emphasized that, even if the simulation can reproduce some experimental results, this does not exclude the possibility that unknown pathways or molecules are additionally needed for the induction of cerebellar LTD. In any case, experiments together with the approach using kinetic simulation should greatly improve our understanding of the behaviors of the complex biochemical reactions underlying cerebellar LTD.

\section{APPENDIX 1: The inputs used in this study}

The temporal waveforms of inputs such as $\mathrm{Ca}^{2+}$, NO and glutamate used in this study are shown (Fig. 6). The concentration of $\mathrm{CRF}$ is assumed to be constantly $0.1 \mu \mathrm{M}$ during the stimulation because no data were available. In the case of the stimulation of $\mathrm{PF}$ or $\mathrm{CF}$ alone, $\mathrm{Ca}^{2+}$ peak concentrations are reduced to 2.3 and $2.6 \%$, respectively, according to an earlier report (Wang et al., 2000).

\section{APPENDIX 2: Summary of the kinetic simulation results and the corresponding experimental results together with the predictions}

The phosphorylation of AMPA receptors and the changes of EPSC (Chen and Thompson, 1995) induced by the conjunctive stimulation of PF and CF (Fig. 2)

The initial and the intermediate phases are reproduced by the kinetic simulation. The late phase is not reproduced because the late phase of cerebellar LTD has been shown to require gene expression and protein synthesis (Linden, 1996), and our kinetic simulation does not include both of them. The time courses of the activation of PKC and PP2A have yet to be determined. However, antibodies against the phosphorylated AMPA receptors (Matsuda et al., 2000) and the phosphorylated G-substrate, an inhibitor of PP2A, should allow us to measure these time courses in the future.

The conjunctive stimulation of PF and CF induces the stable phosphorylation of AMPA receptors in cerebellar LTD (Fig. 3)

In the kinetic simulation, neither the initial nor intermediate phase is significantly induced by the stimulation of either PF or $\mathrm{CF}$ alone. However, an experimental stimulation similar to the $\mathrm{CF}$ alone stimulation in the kinetic simulation has been shown to induce an initial sharp decrease in the EPSC (Daniel et al., 1992; 
Hemart et al., 1994). The failure of the kinetic simulation to reproduce this observation raises the possibility that other mechanisms in addition to the phosphorylation of AMPA receptors underlie the initial phase of cerebellar LTD. It has been shown that increasing $\mathrm{Ca}^{2+}$ in dendrite activates $\mathrm{Ca}^{2+}$-dependent $\mathrm{K}^{+}$ channels, resulting in shunting PF-induced EPSP (Gruol et al., 1991; Khodakhah and Ogden, 1993; Muller et al., 1998). Additionally, it has been shown recently that the activation of postsynaptic mGluR1 in PC dendrites transiently depresses synaptic transmissions at $\mathrm{PF}-\mathrm{PC}$ synapses by a presynaptic mechanism involving $\mathrm{Ca}^{2+}$ increases in PC dendrites and retrograde signaling (Levenes et al., 2000) and that retrograde inhibition of $\mathrm{Ca}^{2+}$ influx occurs through endogenous cannabinoids at excitatory synapse on PCs (Kreitzer and Regehr, 2001). These mechanisms are likely to be the main mechanisms for the expression of the initial phase of cerebellar LTD.

\section{Bistability of the phosphorylation of AMPA receptors in cerebellar LTD (Fig. 4)}

In the kinetic simulation, the phosphorylation of AMPA receptors by PKC shows bistability. Because bistability in the phosphorylation of AMPA receptors has not been shown experimentally, this result provides an interesting testable prediction of bistability in the phosphorylation of AMPA receptors in cerebellar LTD. A recently established antiphosphorylated AMPA receptors antibody (Matsuda et al., 1999) should allow us to test this prediction in the future.

\section{The role of each signaling molecule and pathway in the induction of the phosphorylation of AMPA receptor in the cerebellar LTD (Fig. 5)}

In the kinetic simulation, the roles of $\mathrm{PKC}, \mathrm{NO}, \mathrm{Ca}^{2+}$, and $\mathrm{PLA}_{2}$ are basically consistent with the experimental observations (Sakurai, 1990; Konnerth et al., 1992; Lev-Ram et al., 1997; De Zeeuw et al., 1998). However, without $\mathrm{NO}$ or $\mathrm{Ca}^{2+}$ elevation, a small peak in the phosphorylation of the AMPA receptors can still be observed in the kinetic simulation, whereas this initial peak is not observed by the addition of blockers of $\mathrm{Ca}^{2+}$ (Sakurai, 1990; Eilers et al., 1997) or NO (Lev-Ram et al., 1997). As indicated above, these discrepancies raise the possibility that other mechanisms underlie the expression of the initial phase of cerebellar LTD.

In addition, DAG contributes to the stable phosphorylation of AMPA receptors in both the initial and intermediate phases in the kinetic simulation. Experimentally, it is difficult to analyze the role of DAG because no specific inhibitors of DAG are available. Moreover, the inactivation of PLC, which produces both $\mathrm{DAG}$ and $\mathrm{IP}_{3}$, results in the depletion of both products. Consequently, the simulation is useful for analyzing the role of signal transduction pathways, which is experimentally difficult to analyze.

\section{REFERENCES}

Aiba A, Kano M, Chen C, Stanton ME, Fox GD, Herrup K, Zwingman TA, Tonegawa S (1994) Deficient cerebellar long-term depression and impaired motor learning in mGluR1 mutant mice. Cell 79:377-388.

Ajima A, Ito M (1995) A unique role of protein phosphatases in cerebellar long-term depression. NeuroReport 6:297-300.

Ariano MA, Lewicki JA, Brandwein HJ, Murad F (1982) Immunohistochemical localization of guanylate cyclase within neurons of rat brain. Proc Natl Acad Sci USA 79:1316-1320.

Bhalla US, Iyengar R (1999) Emergent properties of networks of biological signaling pathways. Science 283:381-387.

Bredt DS, Snyder SH (1992) Nitric oxide, a novel neuronal messenger. Neuron 8:3-11.

Brorson JR, Manzolillo PA, Miller RJ (1994) $\mathrm{Ca}^{2+}$ entry via
AMPA/KA receptors and excitotoxicity in cultured cerebellar Purkinje cells. J Neurosci 14:187-197.

Chen C, Thompson RF (1995) Temporal specificity of long-term depression in parallel fiber-Purkinje synapses in rat cerebellar slice. Learn Mem 2:185-198.

Chen C, Kano M, Abeliovich A, Chen L, Bao S, Kim JJ, Hashimoto K, Thompson RF, Tonegawa S (1995) Impaired motor coordination correlates with persistent multiple climbing fiber innervation in PKC gamma mutant mice. Cell 83:1233-1242.

Conquet F, Bashir ZI, Davies CH, Daniel H, Ferraguti F, Bordi F, Franz-Bacon K, Reggiani A, Matarese V, Conde F, Collingridge GL, Crepel F (1994) Motor deficit and impairment of synaptic plasticity in mice lacking mGluR1. Nature 372:237-243.

Crepel F, Jaillard D (1991) Pairing of pre- and postsynaptic activities in cerebellar Purkinje cells induces long-term changes in synaptic efficacy in vitro. J Physiol (Lond) 432:123-141.

Crepel F, Krupa M (1988) Activation of protein kinase C induces a long-term depression of glutamate sensitivity of cerebellar Purkinje cells. An in vitro study. Brain Res 458:397-401.

Daniel H, Hemart N, Jaillard D, Crepel F (1992) Coactivation of metabotropic glutamate receptors and of voltage-gated calcium channels induces long-term depression in cerebellar Purkinje cells in vitro. Exp Brain Res 90:327-331.

Daniel H, Levenes C, Crepel F (1998) Cellular mechanisms of cerebellar LTD. Trends Neurosci 21:401-407.

Detre JA, Nairn AC, Aswad DW, Greengard P (1984) Localization in mammalian brain of G-substrate, a specific substrate for guanosine $3^{\prime}, 5^{\prime}$-cyclic monophosphate-dependent protein kinase. J Neurosci 4:2843-2849.

De Zeeuw CI, Hansel C, Bian F, Koekkoek SK, van Alphen AM, Linden DJ, Oberdick J (1998) Expression of a protein kinase C inhibitor in Purkinje cells blocks cerebellar LTD and adaptation of the vestibuloocular reflex. Neuron 20:495-508.

Ehlers MD (2000) Reinsertion or degradation of AMPA receptors determined by activity-dependent endocytic sorting. Neuron 28:511-525.

Eilers J, Takechi H, Finch EA, Augustine GJ, Konnerth A (1997) Local dendritic $\mathrm{Ca}^{2+}$ signaling induces cerebellar long-term depression. Learn Mem 4:159-168.

Ekerot CF, Kano M (1985) Long-term depression of parallel fibre synapses following stimulation of climbing fibres. Brain Res 342:357-360.

Endo S, Suzuki M, Sumi M, Nairn AC, Morita R, Yamakawa K, Greengard P, Ito M (1999) Molecular identification of human G-substrate, a possible downstream component of the cGMP-dependent protein kinase cascade in cerebellar Purkinje cells. Proc Natl Acad Sci USA 96:2467-2472.

Fiala JC, Grossberg S, Bullock D (1996) Metabotropic glutamate receptor activation in cerebellar Purkinje cells as substrate for adaptive timing of the classically conditioned eye-blink response. J Neurosci 16:3760-3774.

Finch EA, Augustine GJ (1998) Local calcium signalling by inositol1,4,5-trisphosphate in Purkinje cell dendrites. Nature 396:753-756.

Gruol DL, Jacquin T, Yool AJ (1991) Single-channel K+ currents recorded from the somatic and dendritic regions of cerebellar Purkinje neurons in culture. J Neurosci 11:1002-1015.

Hall KU, Collins SP, Gamm DM, Massa E, DePaoli-Roach AA, Uhler MD (1999) Phosphorylation-dependent inhibition of protein phosphatase-1 by G-substrate. A Purkinje cell substrate of the cyclic GMP-dependent protein kinase. J Biol Chem 274:3485-3495.

Hayashi T, Umemori H, Mishina M, Yamamoto T (1999) The AMPA receptor interacts with and signals through the protein tyrosine kinase Lyn. Nature 397:72-76.

Hemart N, Daniel H, Jaillard D, Crepel F (1994) Properties of glutamate receptors are modified during long-term depression in rat cerebellar Purkinje cells. Neurosci Res 19:213-221.

Hirano T, Kasono K, Araki K, Mishina M (1995) Suppression of LTD in cultured Purkinje cells deficient in the glutamate receptor delta 2 subunit. NeuroReport 6:524-526.

Ichise T, Kano M, Hashimoto K, Yanagihara D, Nakao K, Shigemoto R, Katsuki M, Aiba A (2000) mGluR1 in cerebellar Purkinje cells essential for long-term depression, synapse elimination, and motor coordination. Science 288:1832-1835

Ito M (1989) Long-term depression. Annu Rev Neurosci 12:85-102.

Ito M, Karachot L (1992) Protein kinases and phosphatase inhibitors mediating long-term desensitization of glutamate receptors in cerebellar Purkinje cells. Neurosci Res 14:27-38.

Kano M, Kato M (1987) Quisqualate receptors are specifically involved in cerebellar synaptic plasticity. Nature 325:276-279.

Karachot L, Kado RT, Ito M (1994) Stimulus parameters for induction of long-term depression in in vitro rat Purkinje cells. Neurosci Res 21:161-168.

Kashiwabuchi N, Ikeda K, Araki K, Hirano T, Shibuki K, Takayama C, Inoue Y, Kutsuwada T, Yagi T, Kang Y, Aizawa S, Mishina M (1995) Impairment of motor coordination, Purkinje cell synapse formation, and cerebellar long-term depression in GluR delta 2 mutant mice. Cell $81: 245-252$. 
Kawasaki H, Fujii H, Gotoh Y, Morooka T, Shimohama S, Nishida E, Hirano T (1999) Requirement for mitogen-activated protein kinase in cerebellar long term depression. J Biol Chem 274:13498-13502.

Kawato M (1999) Internal models for motor control and trajectory planning. Curr Opin Neurobiol 9:718-727.

Khodakhah K, Ogden D (1993) Functional heterogeneity of calcium release by inositol trisphosphate in single Purkinje neurones, cultured cerebellar astrocytes, and peripheral tissues. Proc Natl Acad Sci USA 90:4976-4980.

Kohda K, Inoue T, Mikoshiba K (1995) $\mathrm{Ca} 2+$ release from $\mathrm{Ca} 2+$ stores, particularly from ryanodine-sensitive $\mathrm{Ca} 2+$ stores, is required for the induction of LTD in cultured cerebellar Purkinje cells. J Neurophysiol 74:2184-2188.

Konnerth A, Dreessen J, Augustine GJ (1992) Brief dendritic calcium signals initiate long-lasting synaptic depression in cerebellar Purkinje cells. Proc Natl Acad Sci USA 89:7051-7055.

Kotera J, Yanaka N, Fujishige K, Imai Y, Akatsuka H, Ishizuka T, Kawashima K, Omori K (1997) Expression of rat cGMP-binding cGMP-specific phosphodiesterase mRNA in Purkinje cell layers during postnatal neuronal development. Eur J Biochem 249:434-442.

Kotera J, Fujishige K, Omori K (2000) Immunohistochemical localization of cGMP-binding cGMP-specific phosphodiesterase (PDE5) in rat tissues. J Histochem Cytochem 48:685-694.

Kreitzer AC, Regehr WG (2001) Retrograde inhibition of presynaptic calcium influx by endogenous cannabinoids at excitatory synapses onto purkinje cells. Neuron 29:717-727.

Levenes C, Daniel H, Crepel F (2000) Postsynaptic mGluR1 depress parallel fibers to Purkinje cells synaptic transmission by a retrograde presynaptic mechanism. Soc Neurosci Abstr 332:4.

Lev-Ram V, Jiang T, Wood J, Lawrence DS, Tsien RY (1997) Synergies and coincidence requirements between NO, cGMP, and $\mathrm{Ca} 2+$ in the induction of cerebellar long-term depression. Neuron 18:1025-1038.

Linden DJ (1995) Phospholipase A2 controls the induction of short-term versus long-term depression in the cerebellar Purkinje neuron in culture. Neuron 15:1393-1401.

Linden DJ (1996) A protein synthesis-dependent late phase of cerebellar long-term depression. Neuron 17:483-490.

Linden DJ, Connor JA (1991) Participation of postsynaptic PKC in cerebellar long-term depression in culture. Science 254:1656-1659.

Linden DJ, Connor JA (1993) Cellular mechanisms of long-term depression in the cerebellum. Curr Opin Neurobiol 3:401-406.

Linden DJ, Connor JA (1995) Long-term synaptic depression. Annu Rev Neurosci 18:319-357.

Linden DJ, Dickinson MH, Smeyne M, Connor JA (1991) A long-term depression of AMPA currents in cultured cerebellar Purkinje neurons. Neuron 7:81-89.

Linden DJ, Dawson TM, Dawson VL (1995) An evaluation of the nitric oxide/cGMP/cGMP-dependent protein kinase cascade in the induction of cerebellar long-term depression in culture. J Neurosci 15:5098-5105.

Lisberger SG (1998) Cerebellar LTD: a molecular mechanism of behavioral learning? Cell 92:701-704.

Lohmann SM, Walter U, Miller PE, Greengard P, De Camilli P (1981) Immunohistochemical localization of cyclic GMP-dependent protein kinase in mammalian brain. Proc Natl Acad Sci USA 78:653-657.

Matsuda S, Mikawa S, Hirai H (1999) Phosphorylation of serine-880 in GluR2 by protein kinase $C$ prevents its $C$ terminus from binding with glutamate receptor-interacting protein. J Neurochem 73:1765-1768.

Matsuda S, Launey T, Mikawa S, Hirai H (2000) Disruption of AMPA receptor GluR2 clusters following long-term depression induction in cerebellar Purkinje neurons. EMBO J 19:2765-2774.

Midtgaard J, Lasser-Ross N, Ross WN (1993) Spatial distribution of $\mathrm{Ca} 2+$ influx in turtle Purkinje cell dendrites in vitro: role of a transient outward current. J Neurophysiol 70:2455-2469.

Miyakawa H, Lev-Ram V, Lasser-Ross N, Ross WN (1992) Calcium transients evoked by climbing fiber and parallel fiber synaptic inputs in guinea pig cerebellar Purkinje neurons. J Neurophysiol 68:1178-1189.

Miyata M, Okada D, Hashimoto K, Kano M, Ito M (1999)
Corticotropin-releasing factor plays a permissive role in cerebellar long-term depression. Neuron 22:763-775.

Miyata M, Finch EA, Khiroug L, Hashimoto K, Hayasaka S, Oda SI, Inouye M, Takagishi Y, Augustine GJ, Kano M (2000) Local calcium release in dendritic spines required for long-term synaptic depression. Neuron 28:233-244.

Muller YL, Reitstetter R, Yool AJ (1998) Regulation of $\mathrm{Ca}^{2+}$ dependent $\mathrm{K}^{+}$channel expression in rat cerebellum during postnatal development. J Neurosci 18:16-25.

Mumby MC, Green DD, Russell KL (1985) Structural characterization of cardiac protein phosphatase with a monoclonal antibody. Evidence that the $\mathrm{Mr}=38,000$ phosphatase is the catalytic subunit of the native enzyme(s). J Biol Chem 260:13763-13770.

Nairn AC, Hemmings Jr HC, Greengard P (1985) Protein kinases in the brain. Annu Rev Biochem 54:931-976.

Nishizuka Y (1992) Intracellular signaling by hydrolysis of phospholipids and activation of protein kinase C. Science 258:607-614.

Rossant CJ, Pinnock RD, Hughes J, Hall MD, McNulty S (1999) Corticotropin-releasing factor type 1 and type 2alpha receptors regulate phosphorylation of calcium/cyclic adenosine $3^{\prime}, 5^{\prime}$-monophosphate response element-binding protein and activation of p42/p44 mitogenactivated protein kinase. Endocrinology 140:1525-1536.

Ruth P, Wang GX, Boekhoff I, May B, Pfeifer A, Penner R, Korth M, Breer H, Hofmann F (1993) Transfected cGMP-dependent protein kinase suppresses calcium transients by inhibition of inositol 1,4,5trisphosphate production. Proc Natl Acad Sci USA 90:2623-2627.

Sakurai M (1990) Calcium is an intracellular mediator of the climbing fiber in induction of cerebellar long-term depression. Proc Natl Acad Sci USA 87:3383-3385.

Shibuki K, Kimura S (1997) Dynamic properties of nitric oxide release from parallel fibres in rat cerebellar slices. J Physiol (Lond) 498:443-452.

Shibuki K, Gomi H, Chen L, Bao S, Kim JJ, Wakatsuki H, Fujisaki T, Fujimoto K, Katoh A, Ikeda T, Chen C, Thompson RF, Itohara S (1996) Deficient cerebellar long-term depression, impaired eyeblink conditioning, and normal motor coordination in GFAP mutant mice. Neuron 16:587-599.

Stone JR, Marletta MA (1996) Spectral and kinetic studies on the activation of soluble guanylate cyclase by nitric oxide. Biochemistry 35:1093-1099.

Takechi H, Eilers J, Konnerth A (1998) A new class of synaptic response involving calcium release in dendritic spines. Nature 396:757-760.

Turko IV, Francis SH, Corbin JD (1998) Binding of cGMP to both allosteric sites of cGMP-binding cGMP-specific phosphodiesterase (PDE5) is required for its phosphorylation. Biochem J 329:505-510.

Wang SS, Denk W, Hausser M (2000) Coincidence detection in single dendritic spines mediated by calcium release. Nat Neurosci 3:1266-1273.

Wang X, Robinson PJ (1997) Cyclic GMP-dependent protein kinase and cellular signaling in the nervous system. J Neurochem 68:443-456.

Wang YT, Linden DJ (2000) Expression of cerebellar long-term depression requires postsynaptic clathrin-mediated endocytosis. Neuron 25:635-647.

Wolin MS, Wood KS, Ignarro LJ (1982) Guanylate cyclase from bovine lung. A kinetic analysis of the regulation of the purified soluble enzyme by protoporphyrin IX, heme, and nitrosyl-heme. J Biol Chem 257:13312-13320.

Wood J, Garthwaite J (1994) Models of the diffusional spread of nitric oxide: implications for neural nitric oxide signalling and its pharmacological properties. Neuropharmacology 33:1235-1244.

Xia J, Chung HJ, Wihler C, Huganir RL, Linden DJ (2000) Cerebellar long-term depression requires PKC-regulated interactions between GluR2/3 and PDZ domain-containing proteins. Neuron 28:499-510.

York RD, Yao H, Dillon T, Ellig CL, Eckert SP, McCleskey EW, Stork PJ (1998) Rap1 mediates sustained MAP kinase activation induced by nerve growth factor. Nature 392:622-626. 